\title{
Organizational Contact Effective Date Range
}

National Cancer Institute

\section{Source}

National Cancer Institute. Organizational Contact Effective Date Range. NCI Thesaurus.

Code C93879.

The date and time span for when the organizational contact is active. 